\author{
RAÇA E PSIQUIATRIA: \\ UMA ANÁLISE GENEALÓGICA DA QUESTÃO RA- \\ CIAL NA PSIQUIATRIA BRASILEIRA \\ RACE AND PSYCHIATRY: A GENEALOGICAL ANALYSIS \\ OF THE RACIAL QUESTION IN THE BRAZILIAN PSYCHIATRY
}

Silvio de Azevedo Soares*

RESUMO: O propósito deste trabalho é problematizar a tematização da questão racial na psiquiatria brasileira. A partir do debate sobre raça e racismo (presente em Fredrickson, Hund e Wade), esse trabalho busca analisar a noção de raça e racismo a partir do quadro analítico desenvolvido por Michel Foucault. Nesse sentido, o objetivo desse trabalho é compreender qual a especificidade da questão racial e do negro nas práticas e discursos da psiquiatria brasileira entre o final do século XIX e início do século XX. Em termos metodológicos, considerou-se a psiquiatria como um dispositivo: uma rede de práticas de poder, discursos de saber e modos de concepção de sujeitos. Assim, nos discursos e nas práticas psiquiátricas desse período, analisamos como características físicas e fenotípicas de indivíduos e grupos negros foram operacionalizadas, submetendo esses sujeitos à condições de inferioridade e de desigualdade. Por último, buscamos apresentar contribuições para as possíveis reflexões sobre a relação entre as práticas psiquiátricas de racismo interno e a proposta de "branqueamento" da nação (compreendendo-a como uma estratégia biopolítica de gestão da população brasileira).

Palavras chave: Raça; Racismo; Negro; Psiquiatria; Genealogia.

\footnotetext{
* Mestrando no Programa de Pós-graduação em Ciências Sociais da Universidade Estadual Paulista "Júlio de Mesquita Filho" (UNESP), Campus Marília; Pesquisador do Observatório de Segurança Pública Universidade Estadual Paulista "Júlio de Mesquita Filho" (OSP-UNESP), Marília, SP, Brasil: E-mail: silvioaz@hotmail.com
} 
ABSTRACT: The purpose of this paper is to problematize the theme of the racial question in Brazilian psychiatry. As of the debate on race and racism (present in Fredrickson, Hund and Wade), this work seeks to analyze the notion of race and racism from the analytical framework developed by Michel Foucault. The objective of this paper is to understand the specificity of racial and black issues in Brazilian psychiatry practices and discourses between the late nineteenth and early twentieth century. In methodological terms, psychiatry was considered as a dispositive: a network of power practices, discourses of knowledge and modes of conception of subjects. Thus, in the discourses and psychiatric practices of this period, we analyzed how physical and phenotypic characteristics of black individuals and groups were operationalized, subjecting these subjects to conditions of inferiority and inequality. Finally, we present contributions to the possible reflections on the relationship between the psychiatric practices of internal racism and the proposal of "whitening" the nation (understanding it as a biopolitical strategy for the management of the Brazilian population).

Keywords: Race; Racism; Black; Psychiatry; Genealogy.

\section{I) INTRODUÇÃO}

"Sem fazer monopólio, os loucos são da proveniência mais diversa, originando-se em geral das camadas mais pobres da nossa gente pobre. São de imigrantes italianos, portugueses e outros mais exóticos, são os negros, os roceiros que teimam em dormir pelos desvãos das janelas sobre uma esteira esmolambada e uma manta sórdida." (Lima Barreto, 2010, p.48).

A partir do contexto de debate sobre raça e racismo (Fredrickson, 2004, Hund, 2003; Wade, 1993) que aponta a presença de poucos consensos (raça como categoria construída socialmente) e mais divergências (tal fenômeno deve ser compreendido como um fato social, construção ideológica ou metáfora discursiva? Como evento de caráter ocidental ou universal?) esse trabalho pretende compreen- 
der e analisar a noção de raça e racismo a partir do quadro analítico desenvolvido por Michel Foucault.

Nessa perspectiva, compreenderemos raça como uma categoria histórica de sujeição, produto de dispositivos de poder-saber específicos (nesse trabalho, de forma específica, a psiquiatria), que realizase sobre corpos de sujeitos (com suas características físicas e traços fenotípicos), em relações dissimétricas de poder que intencionam relações de subjugação do outro.

Assim, o objetivo desse trabalho é compreender qual a especificidade da questão racial e do negro nas práticas e discursos da psiquiatria brasileira (amparada nas teorias do alienismo, do organicismo e da degenerescência), entre o final do século XIX e início do século $\mathrm{XX}$, período do fim da escravidão, de constituição da República da introdução das teorias raciais no país. Negro que, nesse momento, estava presente no interior do espaço psiquiátrico, em companhia de outros personagens oriundos da pobreza, como na descrição dos internos do Hospital Nacional de Alienados do Rio de Janeiro realizada por Lima Barreto (que teve, pelo menos, duas passagens por essa instituição, em 1914 e 1919).

Compreendendo então a psiquiatria como um dispositivo de poder-saber-modo de subjetivação (Foucault, 2016b; Dreyfus, Rabinow, 1995), pretendemos analisar alguns pontos dos discursos (de forma específica, os discursos dos psiquiatras Nina Rodrigues, Franco da Rocha, Belford Roxo e Juliano Moreira) e das técnicas psiquiátricas (com destaque para as práticas no Asilo dos Alienados São João de Deus, em Salvador, e no Hospital Psiquiátrico do Juquery, em São Paulo), destacando suas referências às questões de raça e do negro.

Levantamos dados e informações em textos que se debruçaram sobre a psiquiatria nesse período histórico brasileiro (Cunha, 1986, 1990; Babrbosa, 1992; Engel, 1999, 2001; Portocarrero, 2002; Lobo, 2008), mas que realizaram uma análise de caráter mais geral, não especificando a questão do negro. Dessa forma, a relevância desse trabalho situa-se na possibilidade de apontar, através de uma revisão bibliográfica das obras acima citadas, como a noção de raça foi operacionalizada e capturada nas tramas da psiquiatria. 
A partir de alguns dados sobre as internações no Hospício do Juquery (Barbosa, 1992), apresentamos números sobre mortes de negros no interior dessa instituição. Produção de mortes pelo dispositivo psiquiátrico compreendido enquanto instrumento da lógica do

Enfim, neste trabalho buscamos trazer subsídios para as possíveis reflexões sobre a relação entre as práticas psiquiátricas de racismo interno e a proposta de "branqueamento" da nação (compreendendo-a como uma estratégia biopolítica de gestão da população brasileira).

\section{II) MARCO TEÓRICO-CONCEITUAL Às voltas com "raça" $e$ "racismo"}

A noção de "raça" - como categoria de compreensão das especificidades corporais e culturais de sujeitos e grupos étnico-sociais, com as consequentes atribuições de inferioridade e desvantagens ao outro e de superioridade e privilégios a quem, a partir das diferenças com relação a si, denomina e classifica a alteridade - é consensualmente entendida, entre os especialistas que se debruçam sobre o tema, como uma construção social (Hund, 2013, p. 12).

$\mathrm{Na}$ espécie humana, enquanto complexo genótipo, não há qualquer característica que possa ser classificada cientificamente a partir da noção biológica de raça. Segundo o geneticista brasileiro Sérgio Pena, "toda a discussão racial depende de 0,0005-0,001\% do genoma humano!” (Pena, 2005, p. 336). Ou seja, não há nenhum embasamento biológico para o conceito de raças humanas (Guimarães, 2002, p. 50). Nessa mesma perspectiva, coloca o sociólogo alemão Wulf Hund que a natureza não deu origem à raça: "Nature did not give rise to race.” (p. 11).

No entanto, muito antes da consolidação do conceito biológico de raça no século XIX, diferenças culturais e/ou fenotípicas foram apreendidas em práticas sociais de inferiorização e de desigualdade: a utilização da noção de "barbarismo" na Grécia Antiga para distinguir os gregos de outros povos (Seyferth, 2002, p. 18); a existência de

1 Segundo Seyferth (p. 20), a dicotomia entre bárbaros e civilizados foi resultado lógico dessa noção, com a utilização do conceito de "bárbaro", em distintos casos, como denominador de inferioridade. 
narrativas e relatos sobre as diferenças e desigualdades entre sujeitos no Egito Antigo, nos povos americanos pré-colombianos, na China e na Índia (Hund, p.8).

Segundo o antropólogo Kabengele Munanga (2003), a palavra raça possui origem etimológica no latim rattio, que significa sorte, categoria, espécie. Essa noção não possuía até o século XVII sua definição biológica: raça era uma noção utilizada na Europa medieval para designar a descendência e a linhagem de famílias nobres. O uso do termo raça para classificar espécies animais e vegetais foi consolidado nas Ciências Naturais pelo naturalista sueco Carl Von Lineu em 1735. Contudo, anteriormente, em 1684, um médico francês, François Bernier, propõe o emprego do termo no sentido biológico para a divisão racial dos grupos humanos a partir dos contrastes físico-corporais - sendo a cor de pele considerada o principal critério na categorização de raças nesse momento.

$\mathrm{Na}$ Europa Ocidental do final do século XVIII e início do XIX, com o desenvolvimento da anatomia comparada, dos estudos naturalistas e dos métodos antropométricos (com o acréscimo de outros parâmetros, ao critério da cor da pele, para definição racial: a forma de nariz, dos lábios, do queixo, do crânio...), raça enquanto noção biológica torna-se o paradigma predominante na compreensão das diferenças físicas e culturais entre grupos humanos. A partir de "uma explicação biológica para a diversidade cultural" (Seyferth, p. 23, grifo da autora), produz-se a hierarquização dos grupos humanos e a atribuição de diferentes níveis intelectuais, morais e culturais às supostas raças:

"Assim, os indivíduos da raça "branca", foram decretados coletivamente superiores aos da raça "negra" e "amarela", em função de suas características físicas hereditárias, tais como a cor clara da pele, o formato do crânio (dolicocefalia), a forma dos lábios, do nariz, do queixo, etc. que segundo pensavam, os tornam mais bonitos, mais inteligentes, mais honestos, mais inventivos, etc. e consequentemente mais aptos para dirigir e dominar as outras raças, principalmente a negra mais escura de todas e consequentemente 
considerada como a mais estúpida, mais emocional, menos honesta, menos inteligente e portanto a mais sujeita à escravidão e a todas as formas de dominação.” (Munanga, 2003).

Ou seja, com a transformação da noção de raça em conceito biológico, as diferenças e desigualdades entre grupos humanos buscam ser legitimados em discursos biologizantes e naturalistas ${ }^{2}$.

Hofbauer relaciona a emergência da noção biológica de raça ao contexto de "um processo amplo de secularização que se expressava em dramáticas transformações sociais, políticas e econômicas na Europa" (2003, p. 74). Processo amplo de secularização que se relaciona: às descobertas do século XV (ameríndios, melanésios, etc.) que colocam em xeque o conceito religioso de humanidade ("descendentes de Adão") presente na Europa do período; ao Iluminismo enquanto movimento que contesta o monopólio religioso do conhecimento. Seyferth indica ainda que o desenvolvimento do conceito de raça e das teorias raciais na Europa do século XIX, no contexto do colonialismo e imperialismo, "foram úteis aos seus ideólogos para impor a dominação política e econômica aos povos colonizados" (p. 26).

Em suma, para Hund (p. 19), a ideia de raça é construção do racismo, enquanto complexo histórico de práticas sociais de inferiorização e exclusão. "Racismo" que não é passível de ser definido de maneira abstrata, mas que necessita ser analisado em cada caso, em sua especificidade histórica.

Enquanto termo para definir práticas de inferiorização a partir da noção de raça, a palavra racismo foi cunhada nos anos 1930 (Seyferth, p. 28), menos como "conceito analítico" do que como "instrumento de luta" na denuncia de práticas peculiares de discriminação e desqualificação social, que operacionalizavam conteúdos biologizantes e deterministas - principalmente a política racial da Alemanha nazista.

No entanto, se à primeira vista, critérios físicos como marcadores raciais e políticas raciais aparentam ser fenômenos datados (séculos XIX e XX, respectivamente) e apesar do consenso quanto 2 De forma semelhante à Muganga, Fredrickson (2004, p. 51) indica que os naturalistas do século XVIII exaltavam os europeus como "perspicazes", "inventivos" e "governados por leis" e desqualificavam e estigmatizavam os negros como "manhosos", "preguiçosos", "negligentes" e "governados pelo capricho". 
à construção social de "raça", Peter Wade (1993) constata que diferenças fenotípicas de indivíduos e grupos ainda são tomadas de forma naturalizada por alguns pesquisadores contemporâneos das relações raciais (p. 18). Diferenças de cor ou pigmentação de pele são exemplos de características de fenótipo que ainda são abordadas em estudos raciais como um dado natural, como se a compreensão de "cor" não decorre-se de categorias culturais ou até mesmo como se a apreensão da ideia de natureza não fosse também uma construção social ${ }^{3}$. Nesse sentido, para Muganga (2003), o conteúdo dos conceitos de negro, branco e mestiço é "etno-semântico, político-ideológico e não biológico." Em outros termos, os usos desses conceitos não possuem o mesmo significado em contextos distintos (como nos Estados Unidos, no Brasil, na África do Sul, na Inglaterra, etc.).

Enfim, as constatações de Wade e Muganga reforçam a proposição de Hund sobre a necessidade de análise de cada caso de práticas racistas, abordando como características e diferenças fenotípicas são construídas e utilizadas por discursos ideológicos, "em contextos históricos e políticos concretos, marcados por relações de poder específicas, e fundam, deste modo, formas de discriminação 'racismos' - específicos.' (Hofbauer, 2003, p. 76).

\section{Contribuição à discussão sobre raça e racismo a partir de Foucault}

Se, por um lado, a compreensão da noção de raça como construção social é consensual, por outro, Hund aponta que há também discordâncias se raça deve ser tomada como fato social, construção ideológica, metáfora discursiva, se a construção de raças deve ser compreendida como fenômeno tipicamente ocidental ou universal (p. 13). Nesse cenário de dissensos, proponho aqui uma compreensão histórico-social de raça a partir do quadro analítico construído por Foucault: raça como categoria de sujeição, produto de dispositivos de poder-saber (nesse trabalho, a psiquiatria), que realiza-se sobre corpos de sujeitos (com suas características físicas e traços

3 Nesse sentido, os trabalhos de Eduardo Viveiro de Castro $(1996,2004)$ são exemplos de como, na perspectiva ameríndia dos povos da floresta amazônica, a natureza é apreendida de formas distintas ao modelo eurocêntrico, que a compreende como realidade "neutra" e "imediata" aos órgãos do sentido. 
fenotípicos), em relações dissimétricas de poder que intencionam relações de subjugação do outro.

Nos trabalhos do pensador ${ }^{4}$ francês Michel Foucault (1926-1984) encontra-se uma série de estudos históricos - em uma perspectiva não apriorística, não essencialista, não teleológica - de como práticas e técnicas de poder se exerceram, em específicos contextos históricos e sociais ${ }^{5}$, sobre a materialidade dos corpos humanos visto que "o controle da sociedade sobre os indivíduos não se opera simplesmente pela consciência ou pela ideologia, mas começa no corpo, com o corpo" (2016a, p. 144).

Em sua fase intelectual denominada genealógica ${ }^{6}$, Foucault (1999) considera o poder não como uma substância, uma entidade que se possa ter, trocar, retomar; o poder se exerce, é ato, é relacional. Como relação social constituinte do corpo social, o poder funciona a partir de uma rede, de uma cadeia de interações entre sujeitos, discursos, saberes, práticas, onde os indivíduos (enquanto intermediários, não somente objetos de poder), exercem, submetem-se ou resistem ao poder.

Para Foucault, o poder não deve ser analisado somente como intencionalidades de repressão, proibição e cerceamento, mas também, nas sociedades modernas, como uma realidade positiva, que constitui discursos e individualidades (1987, p. 172), que produz instrumentos de constituição e acúmulo de saber - como métodos de observação, técnicas de registros, procedimentos de investigação (1999, p. 45). Poder "que é inventivo, um poder que detém em si os princípios de transformação e de inovação.” (2010, p. 45).

\footnotetext{
4 Existe certa dificuldade em situar Foucault, a despeito das inúmeras contribuições teóricas e metodológicas à filosofia e à história. Sobre isso, Foucault, ironicamente, se autointitulava, não como historiador e nem como filósofo, mas como um "pirotécnico", que fabrica alguma coisa que permita avançar, que possa fazer caírem os muros (acadêmicos, científicos, institucionais...): "Considero meus livros como minas, pacotes de explosivos... Espero que sejam!” (Pol-Droit, 2006, p. 79). 5 Nas obras Vigiar e Punir (1987) e História da Sexualidade I: A vontade de saber (1988), por exemplo, Foucault analisa como práticas específicas de poder (prisão enquanto punição penal) e certos discursos sobre a sexualidade constituíram redes próprias de relações entre práticas de poder, saberes e constituição de sujeitos (como "delinquente" e "sujeito de sexualidade", respectivamente).

6 Tornou-se comum, ao menos para fins de introdução à obra de Foucault, comentaristas segmetarem a sua produção em três momentos (Machado, 2016, p. 32; Castro, 2009, p. 264) - periodização não suficientemente precisa já que tais fases estariam articuladas, em balanço do próprio Foucault, em torno do fio condutor do sujeito (Cf. Foucault, 1995, p. 231). Grosso modo, a distinção da trajetória intelectual de Foucault é assim definida: nos anos 1960, uma arqueologia dos saberes, das regras de enunciação e de circulação de discursos; nos anos 1970, uma analítica genealógica sobre os sistemas de poder-saber, sobre os dispositivos de poder que produzem discursos de saber e sujeitos; nos anos 1980, a fase ética de problematização do sujeito, as leituras éticas das práticas de si - como o ser humano, a partir de certas técnicas, pode-se constituir enquanto sujeito.
} 
No sentido de poder como inventivo e produtivo, a constituição do discurso de saber é compreendida a partir de "coerções históricas" de relações de poder - regras de construção, descontinuidades, proibições e interdições (2014, p. 173). O discurso, constituído pelo poder e instrumento do poder, com efeitos políticos sobre corpos e sujeitos.

Dessa maneira, em Foucault, o poder e o saber se implicam e se reforçam mutuamente, funcionam entrelaçadamente: às múltiplas relações de poder que perpassam a sociedade, congregam-se específicos discursos de verdade, produzidos e postos em circulação por tais mecanismos de poder. Tais práticas de poder e discursos de saber, a partir de determinadas instituições (escola, psiquiatria, prisão, etc.), engendram sujeitos ${ }^{7}$ - nas formas pelas quais os seres humanos se concebem e são compreendidos pelo corpo social.

Em outros termos, a perspectiva analítica de Foucault possibilita uma abordagem histórica da subjetividade: compreender o sujeito a partir de definidas relações históricas de discursos de verdade e de relações de poder que constituem específicos modos de subjetivação, formas de objetivação do sujeito: modos nos quais o sujeito apresenta-se como objeto de uma determinada relação de conhecimento e de poder (Castro, p. 408).

Enfim, práticas de poder, discursos de saber e modos de subjetivação que Foucault aborda em uma perspectiva microfísica: não investigar o poder a partir de suas manifestações centrais e estatais, mas uma análise das estratégias de poder investidas nos corpos, dos poderes periféricos e moleculares que não são necessariamente poderes de Estado (Machado, 2016, p. 16).

Deste modo, as proposições de Foucault permite-nos compreender a noção de raça do século XIX como uma categoria produzida e instrumentalizada em uma série de mecanismos de poder (nos hospitais psiquiátricos, nas relações coloniais, por exemplo), operacionalizada pelo discurso científico da época (ciências naturais, biologia, antropometria, antropologia física,...). Raça como uma categoria que realiza uma forma de objetivação do corpo humano, enquanto uma 7 Para Foucault (2003), o sujeito não é compreendido como substância universal a priori. Pelo contrário, Foucault procura apresentar “(...) um ceticismo sistemático a respeito de todos os universais antropológicos" (p. 237), um ceticismo às conjecturas de saber supostamente universais quanto à natureza humana. 
forma dos sujeitos serem compreendidos pelo corpo social. Categoria que numa classificação hierárquica das raças permite vantagens e benesses para alguns, desvantagens, sujeições e malefícios para outros. Por fim, a perspectiva microfísica de análise do poder permite o exame de práticas distintas de racismo, não necessariamente vinculadas ao Estado, em específicos contextos históricos.

De certa forma, essa compreensão de raça inspirada por Foucault pode-se aproximar da discussão contemporânea sobre o tema apresentada no tópico anterior: uma apreensão histórica e específica, não essencialista, do que é corpo e do que é raça, semelhante às proposições de Hund e Wade.

Outro ponto de aproximação da noção aqui proposta é com a concepção de racismo de Fredrikson (2004) a partir de dois componentes, diferença e dissimetria de poder: a percepção de diferença que fornece motivo ou base racional para se usar uma vantagem em termos de poder para tratar o outro de forma que se consideraria cruel ou injusta se aplicada aos membros do próprio grupo (p. 16).

Por fim, no curso "Em defesa da sociedade" (1999) - ocorrido entre janeiro e março de 1976, no Collège de France ${ }^{8}$-, Foucault realizou uma genealogia histórica a respeito das relações de poder e discursos de saber que produziram a noção biológica de raça e o racismo do século XIX, enquanto um elemento dos mecanismos modernos de poder. Foucault descreve que, ao fim das guerras civis e religiosas na Europa do século XVI e XVII, emerge um discurso da guerra das raças, um discurso sobre o caráter binário da sociedade, no qual se é sempre inimigo de alguém. Foucault (p. 71) verifica tal discurso nos puritanos, nos Levellers, em John Lilburne na Inglaterra (como discurso de reivindicação popular e da pequena burguesia no século XVII) e na discussão sobre as origens hereditárias do povo francês (gauleses, germanos ou romanos) presentes em Henri de Boulainvilliers (enquanto discurso de reivindicação da nobreza contra a monarquia administrativa, no final do reinado de Luís XIV).

Foucault (1999) constata que esse discurso da luta entre duas raças distintas se transforma, ao longo do século XIX, em um racis-

8 Foucault lecionou no Collège de France de 1971 até sua morte, em junho de 1984, na cátedra "História dos sistemas de pensamento". 
mo interno, contra membros do próprio grupo, contra aqueles que podem constituir perigos internos para o patrimônio biológico da própria sociedade (p. 73).

Para Foucault, tal transformação no discurso histórico-político da guerra de raças é decorrente da consolidação de uma nova lógica de poder no final do século XVIII e início do século XIX. Foucault denomina essa nova lógica de poder de biopolítica9. Sistema de poder que caracteriza-se por tomar, como objeto de intervenções de poder e controles de saber, os fenômenos e acontecimentos comuns à vida, à espécie humana, à população. Biopolítica que possui, como finalidade, gerir e multiplicar a vida (ampliando as capacidades vitais de certos grupos étnico-sociais).

Com a emergência da biopolítica, o racismo, enquanto conjunto de práticas e discursos, constitui-se como elemento fundamental de poder do Estado. Para Foucault, o racismo de Estado:

"É, primeiro, o meio de introduzir afinal, nesse domínio da vida de que o poder se incumbiu, um corte: o corte entre o que deve viver e o que deve morrer. No contínuo biológico da espécie humana, o aparecimento das raças, a distinção das raças, a hierarquia das raças, a qualificação de certas raças como boas e de outras, ao contrário, como inferiores, tudo isso vai ser uma maneira de fragmentar esse campo biológico de que o poder se incumbiu; uma maneira de defasar, no interior da população, uns grupos em relação aos outros." (1999, p. 304).

Racismo moderno que não relaciona-se à mentalidades e ideologias, mas que faz parte dos mecanismos de poder do Estado. Racismo institucionalizado no funcionamento do Estado moderno. Racismo de Estado, no âmbito do governo, das instituições. Racismo, no exercício da biopolítica, como "condição para que se possa

9 Nas análises históricas sobre os mecanismos de poder na Europa entre fins do século XVII e fins do XIX, Foucault constata uma reconfiguração na estratégia geral de poder: da preponderância de uma lógica de poder denominada "soberania" (que se exercia essencialmente no direito do soberano de causar a morte dos súditos) para a prevalência do "biopoder" (que caracteriza-se por tomar, como objeto, o corpo e a vida do ser humano com a finalidade de "fazer viver": o corpo individualizado sob a "disciplina" - produzindo corpos úteis para o trabalho fabril, por exemplo - e na "biopolítica", os corpos da massa dos sujeitos, da população - nas campanhas de vacinação, por exemplo). 
exercer o direito de matar" $(1999$, p. 306) aqueles que ameaçam o patrimônio biológico-hereditário da sociedade. Eis a especificidade do racismo moderno para Foucault.

\section{III) PERSPECTIVA METODOLÓGICA}

A partir das colocações de Hund que indicam, no lugar de uma conceituação abstrata, a análise de casos historicamente específicos para compreensão do racismo, nesse trabalho - abordando um momento preciso da história brasileira: de 1881 a $1923^{10}$, quando o alienismo, o organicismo e a teoria da degenerescência deram a tônica às práticas psiquiátricas - avaliaremos como a psiquiatria produziu relações sociais de racismo, com inferiorização e exclusão de sujeitos a partir de suas diferenças físicas e fenotípicas.

Posto que o conceito de raça e seus critérios definidores, como cor de pele negra ou branca, "atuam como categorias de inclusão e exclusão, que remetem também a concepções de mundo" (Hofbauer, 2006, p. 46), buscaremos reportar a utilização de tais noções ao seu respectivo contexto histórico-social, visando uma abordagem não naturalizada e essencialista dessa problemática.

Dessa forma, compreenderemos a psiquiatria como um dispositivo, a categoria metodológica foucaultiana para constituição de uma rede heterogênea composta de práticas e técnicas de poder, de discursos, de instituições, de leis, de normas (Foucault, 2016b, p. 364; Dreyfus, Rabinow, 1995, p. 134) - ferramenta metodológica que pode permitir uma análise densa e específica de práticas historicamente contextualizadas de racismo.

Ainda segundo Foucault (2010), o racismo que emerge no fim do século XIX - racismo contra as ameaças internas à sociedade, não contra os riscos externos como no racismo étnico - constituiu-se a partir da conexão da teoria psiquiátrica da degenerescência hereditária com a noção biológica de raça.

\footnotetext{
10 Os marcos históricos dessa pesquisa abrangem o período em que a psiquiatria consolidou-se como especialidade científica autônoma no país, a partir da criação da especialidade médica em psiquiatria na Faculdade Nacional de Medicina do Rio de Janeiro em 1881 até a criação da Liga Brasileira de Higiene Mental em 1923, no Rio de Janeiro, enquanto entidade que fundamentava-se em novos critérios teóricos - no caso, a eugenia (Cf. Cunha, 1986).
} 
“O racismo que nasce na psiquiatria dessa época é o racismo contra o anormal, é o racismo contra os indivíduos, que sendo portadores seja de um estado, seja de um estigma, seja de um defeito qualquer, podem transmitir a seus herdeiros, da maneira mais aleatória, as consequências imprevisiveis do mal que trazem em si. É portanto um racismo que terá por função não tanto a prevenção ou a defesa de um grupo contra outro, quanto a detecção, no interior mesmo de um grupo, de todos os que poderão ser efetivamente portadores do perigo." (p. 277).

Nesse sentido, pretende-se descrever como, no Brasil dos fins do século XIX e início do XX, o dispositivo psiquiátrico (através de práticas de poder e discursos de saber como leis, técnicas psiquiátricas, teorias científicas, instituições como hospícios) operacionalizou a noção de raça, compreendida a partir de Foucault como categoria de sujeição (conforme apresentamos anteriormente), e produziu condições de inferiorização, desigualdade e exclusão para certos sujeitos no interior da sociedade. Em suma, delinear como o dispositivo psiquiátrico contribui na execução de práticas de racismo interno na sociedade brasileira.

Os textos e obras, que utilizaremos como principais unidades de análise (Cunha, 1986, 1990; Barbosa, 1992; Engel, 1999, 2001; Portocarrero, 2002; Lobo, 2008), trataram da psiquiatria no período da Primeira República, mas realizaram uma análise geral, não especificando a questão do negro. Dessa forma, a relevância desse trabalho situa-se na possibilidade apresentar, através de uma revisão bibliográfica das obras mencionadas, como a noção de raça foi operacionalizada e capturada nas tramas da psiquiatria.

Maria Clementina Pereira Cunha $(1986 ; 1990)$ pretendeu analisar e discutir o perfil do Hospício do Juquery e da psiquiatria paulista, no final do século XIX até a década de 1930, no tocante às suas práticas cotidianas de poder e em sua estratégia de disciplinarização das condutas individuais em relação aos problemas urbanos.

Em estudo também sobre o Hospício do Juquery, Rosana Marchin Barbosa (1992) apresenta dados sobre a condição dos internos (origem, sexo, cor de pele, tipo de solicitação da internação, motivos de saída) no período da Primeira República. 
Através da análise dos prontuários médicos e documentos do Hospital Nacional dos Alienados, das teses da Faculdade de Medicina do Rio de Janeiro e dos periódicos e anais sobre doença mental produzidos entre 1830 e 1930, Magali Engel $(1999 ; 2001)$ procurou investigar o processo de constituição do discurso da loucura como doença mental e suas implicações na implantação de novos mecanismos de controle social, como hospícios medicalizados, sob gestão de psiquiatras.

Já Vera Portocarrero (2001) buscou apontar uma descontinuidade no saber e nas práticas psiquiátricas no Brasil no final do século XIX e início do século XX, a partir da obra do médico Juliano Moreira. Para Portocarrero, a emergência do conceito de anormal permitiu a psiquiatria, articulada com uma gestão política do espaço urbano e sua população, abranger não somente a loucura propriamente, mas todo e qualquer desvio do comportamento, como os degenerados, epiléticos, criminosos, sifilíticos e alcoólatras.

Lília Lobo (2008) buscou problematizar e compreender historicamente, em um estudo de fôlego que aborda do século XVI a primeira metade do XX, a questão da deficiência e suas inter-relações com a teratologia social, a religião católica e práticas inquisitoriais, a escravidão, a teoria da degenerescência, a medicina social e com práticas pedagógicas institucionais.

Por fim, as informações sobre dispositivo psiquiátrico apresentadas nessas obras foram reelaboradas em dois eixos de investigação: a) a implicação da noção de raça nos discursos do saber psiquiátrico; b) os resultados desses discursos: os diagnósticos nos quais certos indivíduos foram sujeitados por suas características "raciais" e as técnicas e práticas de poder-saber nas quais foram submetidos no interior do dispositivo psiquiátrico.

\section{IV) DESCRIÇÃO, DISCUSSÃO E ANÁLISE DOS DADOS} $O$ negro e as teorias raciais na sociedade brasileira do final do século XIX e início do século XX.

Ao final do século XIX e nas primeiras décadas do século $\mathrm{XX}$, verifica-se uma série de transformações no cenário social, eco- 
nômico e político da realidade brasileira (Fausto, 1994; Sevcenko, 1998). Ocorre a queda da Monarquia e o processo de constituição do Estado republicano, com a separação entre Estado e Igreja. A industrialização nascente nas cidades de São Paulo e Rio de Janeiro e a rápida urbanização decorrente acarretam novas questões sociais (como o aumento das taxas de desemprego e de casos de endemias e de epidemias de doenças urbanas).

No final do século XIX, após mais de três séculos de cativeiro, ocorre também o fim das relações escravistas no Brasil. Segundo Azevedo (2003), o processo de abolição no Brasil não se preocupou essencialmente com a situação do negro ex-escravo após a emancipação: o argumento principal do abolicionismo brasileiro não baseava-se nas condições do escravo, mas na preocupação com o desenvolvimento e progresso da nação ${ }^{11}$. A partir da crença na ausência de racismo e preconceito de cor no Brasil ${ }^{12}$, o discurso abolicionista presumia simplesmente que os escravos emancipados iriam se integrar facilmente à sociedade, sem necessidade de qualquer apoio (p. 166).

Dessa forma, o fim da escravidão significou para os brasileiros negros uma nova forma de exclusão: não reabsorvidos pelo trabalho urbano livre, não habilitado para a nova ordem social competitiva em construção, o negro foi repelido para as periferias desse novo mercado de trabalho. Em uma das análises sobre a não integração do negro após abolição, aponta Florestan Fernandes (2007) que após a abolição:

“(...) os 'homens de cor' viam-se condenados ao desemprego sistemático, ao trabalho ocasional ou à retribuição degradada, tendo de se acomodar a um estilo de vida que associava, inexoravelmente, a miséria à desorganização social." (p. 137).

Também nesse período, dá-se a introdução das teorias raciais no Brasil (Schwarcz, 1994, p. 43; Fernandes, 2007, p. 137). Com as teorias raciais e a constituição da noção biológica de raça, as diferenças humanas passam a ser apreendidas em modelos biológicos deterministas que

11 Segundo Azevedo (2003) os abolicionistas brasileiros "se preocupavam exclusivamente com o fato do Brasil ter se atrasado na tarefa histórica de alcançar o 'fato universal' da abolição" (p. 148). 12 Ideário do Brasil como paraíso racial construído a partir da perspectiva do abolicionismo estadunidense que compreendia os EUA como inferno racial (Cf. Azevedo, 2003). 
estabelecem rígida correspondência entre caracteres físicos e atributos morais (Schwarcz, p. 65). Tais teorias, seja pela via monogenista ou pela poligenista ${ }^{13}$, colocavam o homem branco europeu como raça mais desenvolvida na evolução biológica (Ferla, 2005, p. 27).

A partir dessas duas perspectivas sobre a origem do homem, desenvolvem-se duas escolas de pensamento racial. O evolucionismo social, fundamentado no monogenismo, compreendia as desigualdades entre os homens como diferenças hierárquicas no desenvolvimento da humanidade como um todo. Já o darwinismo social, baseado no poligenismo, concebia a humanidade dividida em diferentes raças, ontologicamente distintas (Schwarcz, 1993, p. 62).

Mais que apenas introduzidas, as teorias raciais tiveram uma leitura particular e contextualizada à situação política, social e intelectual do Brasil, articulando referenciais aparentemente contraditórios:

"Do darwinismo social adotou-se o suposto da diferença entre as raças e sua natural hierarquia, sem que se problematizassem as implicações negativas da miscigenação. Das máximas do evolucionismo social sublinhou-se a noção de que as raças humanas não permaneciam estacionadas, mas em constante evolução e 'aperfeiçoamento', obliterando-se a ideia de que a humanidade era uma." (Schwarcz, 1993, p. 18).

Segundo Azevedo (p. 178), em meio à preocupação dos abolicionistas com o destino dos escravos emancipados, conde Gobineau (1816-1882) foi um dos autores do darwinismo social que influenciaram os intelectuais brasileiros. A partir de uma ótica poligenista da origem do homem, Gobineau era um crítico da mistura das diferentes raças humanas, considerando a mestiçagem como a decadência das raças constituidoras originais.

Outro cientista francês que exerceu influência no Brasil foi o evolucionista Armand de Quatrefages (1810-1892). Como Gobineau,

13 Segundo Lilia Moritz Schwarcz (1993, p. 48), duas perspectivas enfrentavam, ao longo do século XIX, o desafio de pensar a origem humana: a) a visão monogenista, fundamentada nas escrituras bíblicas, que supunha que a humanidade possuía uma única gênese, a partir do Éden; b) a visão poligenista que acreditava na existência de vários centros de criação do homem, donde decorreriam as diferentes raças. 
Quatrefages considerava o sujeito pertencente à raça africana como inferior. Mas, diferente das conclusões do primeiro sobre as raças mestiças, Quatrefages previa o desenvolvimento das raças humanas através da "infusão do sangue branco, ou seja, com os elementos etnológicos que tem até o momento levado a seu mais alto grau o desenvolvimento da inteligência humana." (Azevedo, p. 179).

As ideias de Quatrefages foram bem assimiladas pelos abolicionistas brasileiras da segunda metade do século XIX ao defenderem, de forma simultânea, o fim da escravidão com a proposta de imigração europeia, em uma aposta na qual a miscigenação - de maneira diferente do que supunha Gobineau - não levaria à falência da nação. (Schwarcz, 1998, p. 187; Hofbauer, 2003, p. 79).

A proposta de "branqueamento" do povo brasileiro, então delineada, apostava em um novo Brasil, no qual "o sangue caucasiano seria essencial para a felicidade futura do povo brasileiro até então por demais africanizado para conseguir avançar por seus próprio meios em direção ao progresso" (Azevedo, p. 183). De fato, a partir da imigração europeia, acreditava-se na assimilação cultural e física dos europeus e a eliminação dos negros e mestiços mais escuros em um prazo que variava, de acordo com cada teórico, de três gerações a três séculos (Seyferth, p. 36).

Como parte das consequências de tais propostas, a política imigratória subvencionada pelos cofres públicos nesse período acarreta a entrada maciça de imigrantes. Segundo Boris Fausto (1994, pg. 275276), cerca de 3,8 milhões de estrangeiros entraram no Brasil entre 1887 e 1930. Desses imigrantes, os italianos formaram o grupo mais numeroso (35,5\% do total), seguidos de portugueses (29\%) e espanhóis (14\%).

Para o negro, com efeito, a imigração adquire o significado e as proporções de uma calamidade social: proveniente de um processo de abolição que não propiciou seu ajustamento à nova realidade, o ex-escravo viu-se ainda rechaçado da situação de mão de obra em diversas atividades para o imigrante:

“Em 1893, por exemplo, os imigrantes entravam com 79\% do pessoal ocupado nas atividades manufatureiras; com $81 \%$ do pessoal ocupado nas atividades de transporte e conexas; com 71,6\% do pes- 
soal ocupado nas atividades comerciais. (...) Mesmo na área dos serviços menos compensadores, eles [imigrantes] compareciam com cotas altas (eram estrangeiros $58,3 \%$ do pessoal ocupado nos serviços domésticos; e 32\% do pessoal ocupado nos serviços agrícolas). Em conjunto, 71,2\% do pessoal absorvido na estrutura ocupacional da cidade eram estrangeiros." (Fernandes, 2007, p. 137).

Enfim, ao final do século XIX, os negros encontram-se proscritos tanto no novo contexto social e econômico que está se constituindo como nas teorias raciais que "na hierarquia biológica dos esquemas classificatórios fenotípicos, estavam mais próximos das "raças bárbaras" (Seyferth, p. 36). O negro, desconectado dessa nova realidade, passou a ser apreendido como parte das "ameaças urbanas", das "classes perigosas", em companhia de operários, imigrantes desempregados, radicais político, mendigos e prostitutas (Cunha, 1986, p. 40; Carneiro, 1993, p. 148). Sob esse novo rótulo, o negro ex-escravo passa a ser objeto também da psiquiatria.

\section{Dispositivo psiquiátrico no final do século XIX e início do século XX}

No final do século XIX, ocorre também a consolidação da psiquiatria no país, enquanto saber e prática médica (Cunha, 1986, p. 45). Datam desse período: o reconhecimento da psiquiatria enquanto especialidade médica (criação da especialidade na Faculdade de Medicina do Rio de Janeiro através do decreto 8.024 de 12 de março de 1881); a transformação do Hospício Dom Pedro II, no Rio de Janeiro (então sob assistência religiosa da loucura) em Hospital Nacional de Alienados (sob gestão científica da loucura por psiquiatras ${ }^{14}$ ), em 1890; o Estado assume diretamente a gestão de assistência aos doentes mentais com a criação do Serviço de Assistência Médica e Legal de Alienados (decreto $n^{\circ}$ 206A, de 15/02/1890) e a definição de um estatuto legal da doença mental no Brasil (decreto $\mathrm{n}^{\circ} 1.132$, de 22/12/1903).

14 Segundo Cunha (1986), através do alienismo, no final do século XIX e início do século XX, desenvolveu-se a medicalização do cuidado sobre o louco no Brasil, até então em liberdade (como parte da desordem urbana) ou sob custódia em mecanismos penais (cadeias) ou de caridade (Santas Casas). 
Ressalte-se também que as transformações sociais decorrentes do fim da escravidão, da constituição do novo regime político, do crescimento das cidades e dos primeiros passos da industrialização nacional impuseram, ao governo republicano, a necessidade de novos mecanismos de gestão das relações de trabalho, de controle social, de organização do espaço urbano. Novos mecanismos fundados, nesse momento, nos parâmetros científicos, caros à República de inspiração positivista (Cunha, 1990, p. 41). Dessa forma, convergiram-se interesses recíprocos entre a nova república e a psiquiatria, então nascente.

A psiquiatria ao tematizar questões importantes às estratégias de ordem social da República como os comportamentos sexuais, as relações de trabalho, a segurança pública, a questão racial e as manifestações políticas (Engel, 1999, p. 559), permitiu ao Estado brasileiro justificar cientificamente práticas de política social excludentes e segregadoras: destruição de cortiços, higienização das cidades e medidas sanitárias, repressão policial, internamentos (Cunha, 1990, p. 41; Sevcenko, 2010, p. 82).

A partir do final do século XIX, tanto o alienismo (Cunha, 1986, p. 28), quanto o enfoque organicista (Engel, 2001, p. 153) e a teoria da degenerescência (Portocarrero, 2002, p. 48) exerceram influências marcantes na então eclética psiquiatria brasileira.

De forma sintética, o alienismo desenvolveu-se com o psiquiatra francês Philippe Pinel (1745-1826), propondo a compreensão da loucura como uma doença mental (disfunção na ordem dos afetos, excessos passionais), o "tratamento moral" (a disciplina e a laborterarpia, por exemplo) como atividade terapêutica para o domínio racional das paixões e o hospício, local de isolamento e cura do doente. Já psiquiatria organicista, constituída a partir do médico alemão Emil Kraepelin (1856-1926), relaciona a loucura, os vícios morais e outras doenças mentais à causas de ordem biológica (fenômenos físicos e orgânicos). Por último, a teoria da degenerescência, sistematizada pelo médico franco-austriáco Bénédict Morel (1809-1873), explica as doenças mentais a partir das degenerescências (desvios da natureza biológica original do homem, progressiva degeneração mental hereditária entre as gerações). Para Schwarcz, com Morel e 
a ideia de "degeneração racial", não apenas os indivíduos, mas toda espécie humana estava sob o risco da degeneração (1993, p. 255).

\section{Raça no discurso médico-psiquiátrico no final do século XIX e início do século XX}

No discurso médico brasileiro de fins do século XIX, a questão da raça - de forma mais específica, a mistura das raças - apresentava-se como nosso maior mal. Na análise de Schwarcz, a relação entre a raça, saúde e nação é tematizada nos principais centros de formação médica do período (Faculdade de Medicina da Bahia e a Escola Médica do Rio de Janeiro):

"Na Bahia é a raça, ou melhor, o cruzamento racial que explica a criminalidade, a loucura, a degeneração. Já para os médicos cariocas, o simples convívio das diferentes raças que imigraram para o país, com suas diferentes constituições físicas, é que seria o maior responsável pelas doenças, a causa de seu surgimento e o obstáculo à "perfectibilidade” biológica." (Schwarcz, 1993, p. 191).

A despeito das diferenças no debate médico entre essas escolas, não estava em discussão a inferioridade biológica e cultural dos negros (p. 208). Com efeito, por vias distintas, ambas as escolas chegavam a conclusões semelhantes: era necessário cuidar da nação, considerada enquanto raça, e caberia aos médicos tal missão (p. 236).

A temática da raça estava presente também nas teorias e discursos psiquiátricos do período (Cunha, 1986, 1990; Engel, 1999). Em termos gerais, tal questão estava disposta de duas formas. Na primeira, considerada como raça psiquicamente inferior, o negro estava mais sujeito à loucura que outras raças. Nesse sentido, significativa como exemplo dessa abordagem, a observação publicada pela revista "Brazil Medico" da Escola Médica do Rio de Janeiro em 1904:

"Quando nos referimos a uma raça, não individuallismos typos della, tomamol-a em sua acepção mais lata. E assim procedendo 
vemos que a casta negra é o atraso; a branca o progresso a evolução... A demencia, é a forma em que mais avulta os negros. Póde-se dizer que tornam-se elles dementes com muito mais frequência, por sua constituição, que os brancos...” (Brazil Médico, 1904, p. 178 apud Schwarcz, 1993, p. 223).

Em um segundo enfoque, a mestiçagem e a degeneração dela resultante foram tomados como predisposições à loucura (pela constituição de "um tipo híbrido, inferior física e intelectualmente"). Nessa perspectiva, casos de embriaguez, epilepsia e mesmo desobediência civil eram vistos como evidência de que o cruzamento racial leva à degeneração e, por conseguinte, à loucura (Weyler, 2006, p. 21).

Em síntese, para a psiquiatria do final do século XIX e início do século XX, "o negro se torna, mais do que um objeto de estudo, um objeto privilegiado de domesticação pela ciência” (Lobo, 2008, p. 203). Marginalizados social e politicamente, para os ex-escravos, a psiquiatria reservou as "designações inferiores da degeneração, categorias próximas da animalidade ou dos estágios mais primitivos da evolução humana" (Cunha, 1986, p. 31).

\section{Tematização da raça nos discursos psiquiátricos de Nina Rodri- gues, Belford Roxo, Franco da Rocha e Juliano Moreira}

Considerando os discursos não como simples reflexos das práticas sociais, mas como portadores de intencionalidades de poder e como elementos constituintes da realidade (enquanto parte de dispositivos de poder-saber) que se entrelaçam às práticas (Foucault, 2012 , p. 235; 1985, p. 95), procurarei apresentar como alguns psiquiatras do final do século XIX e início do XX tematizaram a questão racial em seus discursos teóricos.

Apesar da escolha, de certa forma, um tanto aleatória, esses nomes tiveram notoriedade na psiquiatria brasileira desse período, tanto na produção teórica como na direção de serviços psiquiátricos.

O maranhense Raimundo Nina Rodrigues (1862-1906) foi médico legista e psiquiatra, formado no Rio de Janeiro em 1886. Tornou- 
se professor da Faculdade de Medicina da Bahia a partir de 1889. Em 1891 passou a ser redator-chefe da "Gazeta Médica da Bahia" (primeira revista de medicina do país, fundada em 1866). Foi também um dos introdutores das técnicas da antropometria e da frenologia no país.

Para Nina Rodrigues, a inferioridade do negro estaria cientificamente comprovada, constituindo um impedimento à civilização do país, "um dos fatores de nossa inferioridade como povo" (Rodrigues, 1933, p. 88 apud Schwarcz, 1993, p. 208).

Nina Rodrigues considerava o cruzamento entre as raças como o principal fator de disseminação da degenerescência. A miscigenação entre raças em diferentes níveis de evolução resultaria em indivíduos mestiços: desequilibrados e inferiores do ponto de vista físico, intelectual e comportamental, "um tipo mental sem valor, que não serve nem para o modo de viver da raça superior, nem para o da raça inferior, que não presta enfim, para gênero algum de vida" (Rodrigues, 1894 apud Engel, 2001, p. 174).

Ou seja, quanto mais mestiço, mais degradado, descaracterizado, débil e sujeito a doenças: "dada a condição de inferioridade mental atribuida ao negro pelas teorias do racismo, a comparação entre ele, o imbecil e o idiota era inevitável" (Lobo, 2008, p. 199). Nesse sentido, em texto de 1894, "As raças humanas e a responsabilidade penal no Brasil", Nina Rodrigues equipara o negro ao louco e à criança, propondo que fosse reconhecido legalmente como irresponsável em termos penais (Engel, 2001, p. 174).

O médico psiquiatria Henrique Belford Roxo (1877-1969), doutor pela Faculdade de Medicina do Rio de Janeiro em 1900, foi diretor do Pavilhão de Observação do Hospital Nacional de Alienados de 1904 a 1907. Foi catedrático de Clínica Psiquiátrica também no Rio de Janeiro e membro titular da Academia Nacional de Medicina.

De forma semelhante a Nina Rodrigues, Belford Roxo também sustentava a inferioridade da raça negra: "É fato comprovado: a raça negra é inferior.” (Roxo, 1904, p. 172 apud Engel, 1999, p.558). Mas, de forma distinta a Nina Rodrigues ${ }^{15}$, em uma contraditória as-

15 Importante assinalar também que diferente de Nina Rodrigues, Roxo assumia uma posição otimista sobre a possibilidade de "evolução biológica" das raças inferiores, de "aprimoramento das raças", mediante a ação da educação e do meio "civilizado" (Engel, 2001, p. 175). 
sociação entre determinismo biológico e ação de influência do meio sócio-cultural, Roxo não considerava os negros e pardos degenerados, mas tipos que não evoluíram, enquanto a raça branca seria o progresso e a evolução (Lobo, 2009, pp. 200; 202). Nesse sentido, em comunicação apresentada no $2^{\circ}$ Congresso Médico Latino-Americano, defendia Roxo:

"Não é a constituição física do preto, a sua cor escura que lhe marcam o ferrete da inferioridade. É a evolução que se não deu. Ficaram retardatários. Ao passo que os brancos iam transmitindo pela herança um cérebro em que as dobras de passagem mais se aprimoravam, em que os neurônios tinham sua atividade mais apurada, os negros que indolentemente se furtaram à emigração, em que a concorrência psíquica era nula, legavam a seus descendentes um cérebro pouco afeito ao trabalho, um órgão que de grandes esforços não era capaz." (Roxo, 1904, p. 182 apud Engel, 2001, p. 174).

Nas causas da alienação mental entre as populações negras no Brasil (em conjunto com o pressuposto biológico de baixo nível intelectual da raça), como um dos fatores de influência do meio social, Roxo considerava os efeitos da "repentina" abolição da escravidão visto que os negros não possuiriam capacidade orgânica suficiente para a vida em liberdade (Engel, 1999, p. 553; Lobo, p. 202).

Entre os diagnósticos de moléstias mentais relacionados à inferioridade evolutiva da raça negra, a partir de observações realizadas no Hospital Nacional de Alienados, Roxo destacava a "imbecilidade", a "idiotia" (Engel, 1999, pp. 553; 555), a demência, o alcoolismo e o delírio (Lobo, 2008, p. 201).

O psiquiatra Francisco Franco da Rocha (1863-1933), também formado pela Escola de Medicina do Rio de Janeiro em 1890, foi o idealizador e fundador do Hospital Psiquiátrico do Juquery. Inaugurado em 1901, o Juquery foi o primeiro hospício em São Paulo a contar com orientação médica para o tratamento de distúrbios psíquicos (Cunha, 1990, p. 50). 
O discurso teórico de Franco da Rocha apresenta um determinismo racial menos acentuado se comparado também a Nina Rodrigues. Em Franco da Rocha, as relações causais entre etiologia da loucura e raça apresentam-se atenuadas por duas questões. Em primeiro lugar, Rocha aponta a dificuldade de estabelecer com rigor a raça do indivíduo e sua influência na loucura: "A promiscuidade de diversas raças brancas entre si, e de algumas destas com a raça negra da África, dá a população do hospício uma heterogeneidade tal que se torna difícil atribuir com segurança a cada raça sua influência na loucura" (Rocha, 1896 apud Barbosa, 1992, p. 99).

Em segundo lugar, Franco da Rocha concebe também as influências do meio social no processo de degeneração. No caso dos negros no Brasil, os efeitos psíquicos da escravidão, resultados dos transtornos e sofrimentos vivenciados, seriam transmitidos geneticamente, como degeneração psíquica hereditária da raça: as proles negras teriam "o cérebro já modificado pelo trabalho cerebral dos antepassados" (Rocha, 1923, p. 10 apud Ribeiro, 2010, p. 68).

Ressalve-se, contudo, que Franco da Rocha não buscou indultar os negros da condição de inferioridade racial, mas chamar a atenção de que a degeneração não possui necessariamente relação com cor de pele ${ }^{16}$. Franco da Rocha não deixou de relacionar a raça negra à certas "formas degenerativas" como a epilepsia, idiotia, imbecilidade (Engel, 1999, p. 554; Lobo, 2008, p. 201) e marcar a inferioridade das condições psíquicas da raça negra: "Até os dias de hoje [1911], o estado rudimentar da mentalidade dessa raça nada evoluiu; ela se mantém ainda muito abaixo, quando comparada com a das raças brancas existentes aqui" (Rocha, 1911, p. 459 apud Ribeiro, 2010, p. 67).

Por fim, o psiquiatra baiano Juliano Moreira (1872-1933). Formado pela Faculdade de Medicina da Bahia (1891), foi diretor do Hospital Nacional de Alienados no Rio de Janeiro entre 1903 e 1930. Em 1896, torna-se redator da revista de medicina "Gazeta Médica da Bahia". Foi também presidente da Academia Brasileira de Ciências entre 1927 e 1929.

16 Preocupação que o aproxima de Morel que, quando diretor do asilo francês de Saint-Yon (18561873), produziu a teoria da degenerescência a partir de observações da situação de miséria em que viviam, na Europa, o proletariado e as populações rurais (Weyler, 2006, p. 22). 
De forma distinta aos psiquiatras anteriores, Juliano Moreira discordava das suposições de relação entre negros, mestiçagem e degeneração e de inferioridade evolutiva da raça negra (Oda, 2001).

Deve-se frisar, no entanto, que Juliano Moreira não colocava em questão a teoria da degenerescência, mas os seus fatores causais, que devem ser buscados no meio de vida do sujeito. Na luta contra a degeneração, devia-se atentar para o alcoolismo, a sífilis, as verminoses, a alimentação e a moralização das massas, das classes pobres - que seriam o principal objeto do cuidado da medicina mental (Portocarrero, 2002, p. 56).

\section{O negro no interior das práticas do dispositivo psiquiátrico}

Tematizados no discurso teórico, buscaremos apresentar nessa seção como a questão racial e o negro foram objetos de técnicas de poder e de sujeição no interior do dispositivo psiquiátrico.

Nos centros urbanos maiores (como Salvador, Rio de Janeiro e São Paulo), a partir das concepções teóricas que norteavam sua prática, a psiquiatria realizou um esquadrinhamento das massas urbanas em busca dos possíveis degenerados e demi-fous. Decompondo essa multidão, o alienismo coloca em destaque e captura em sua rede as possíveis ameaças à ordem urbana: delinquentes, prostitutas, vagabundos, anarquistas, alcoólatras e os negros (Cunha, 1986, p. $51)$.

Como mencionado anteriormente, o dispositivo psiquiátrico designou para os negros as condições mais inferiores de degeneração, os estágios mais primitivos da humanidade. Assim, como a população negra já seria degenerada por sua constituição racial, os negros e os mestiços seriam os mais predispostos à loucura.

Em Salvador, o negro indigente, sofrendo de imbecilidade, de epilepsia e de outras moléstias mentais - como colocavam os discursos psiquiátricos - era capturado nas ruas e entregue às mãos do asilo psiquiátrico. Classificando-se o negro de insano, institucionalizava-se assim a exclusão (Carneiro, 1993, p. 147). 
Fundado em 1874 na cidade de Salvador, o Asilo dos Alienados São João de Deus funcionava como parte de um mecanismo social que permitia retirar das ruas os elementos rotulados de "perigosos" e "nocivos". Submetidos a um estigma duplo, "negro" e "louco", a maioria dos internados do Asilo eram negros, mulatos ou pardos. De acordo com anotações efetuadas nas fichas de entrada, "a maioria foi encontrada vivendo em alto grau de mendicidade e debilitados fisicamente" (Carneiro, p. 147). Capturados como padecendo de alienação mental, demência paralítica e outras "moléstias mentais", dadas as condições físicas e higiênicas do hospício, os asilados morriam de enterocolite, de diarreia, de doenças pulmonares e cardíacas (p. 150).

Em São Paulo, a questão social advinda do crescimento urbano encontrou solução também nas práticas psiquiátricas. Segundo Barbosa (1992), cerca de 99\% das internações no Juquery entre 1898 e 1920 foram executadas através da intervenção do Estado, por meio de autoridades do período em questão - como prefeitos, delegados e chefes de polícia (p. 100).

Os dados do Juquery referentes à cor dos asilados apontam que negros e pardos eram internados em proporção duas vezes maior ao percentual que representavam na população total da cidade de São Paulo (Barbosa, p. 98). Mas, embora os negros constituíssem uma parcela imensa da população, receberam pouca atenção, visto que portariam racialmente os fatores de degeneração. Segundo Cunha (1986, p. 127), os milhares de prontuários de pacientes negros do Juquery estavam praticamente em branco, com anotações telegráficas que designam, em sua maioria, para diagnósticos de degeneração inferior próprios à condição racial: "beócio", "primitivo", "idiotia", "imbecilidade", "débil mental".

A identificação dos internos como negros era estabelecida pelas autoridades médicas a partir da observação de certos caracteres físicos e fenotípicos, considerados marcadores raciais: "a cor preta, platirhinismo [septo nasal largo], cabelo carapinhado, prograthismo mais ou menos pronunciado [projeção das maxilas], lábios grossos e protahidos e pouca barba”. (Barbosa, 1992, p. 98). 
Síntese de uma perspectiva psiquiátrica sobre o negro, o prontuário no Juquery de Maria José, de 22 anos aponta que "os estigmas de degeneração física que apresenta são os comuns da sua raça: lábios grossos, nariz esborrachado, seios enormes, pés chatos” (Cunha, 1986, p. 124).

No interior do hospício, ocupando a posição mais radical de aniquilamento da condição humana, encontram-se as mulheres negras. Portadoras da dupla condição de degeneração, ser mulher e ser negra, são concebidas, pela psiquiatria, em uma condição de dupla inferioridade. Nos diagnósticos e prontuários, tal figura aparece mais próxima da natureza que da qualidade humana: no prontuário de Martha C., 38 anos, o diagnóstico que equivaleu a uma condenação perpétua de vida asilar - "Estigmas físicos de degeneração muito acentuados: é um perfeito tipo de símio" (Cunha, 1986, p. 124).

No Juquery (Cunha, 1986), as condições gerais de higiene e vida também não eram diferentes da situação do Asilo dos Alienados São João de Deus: péssima higiene do hospício, número insuficiente de funcionários, alimentação deficiente, precariedade das instalações (pg. 15), além das elevadas taxas de mortalidade por moléstias contagiantes como tuberculose e infecções gastrointestinais (p. 93).

Segundo Barbosa (1992), entre 1898 e 1920, o Juquery constituiu-se como verdadeiro dispositivo de produção de mortes: dos 5.048 internos que ai foram deixados morrer, 59,23\% faleceram de fato, permanecendo em média 7,12 anos no Juquery (p. 100).

No contexto da lógica do racismo interno e do racismo de Estado (Foucault, 1999, 2010) e dos seus mecanismos de segregação e exclusão contra a população negra, no interior do Juquery (Barbosa, 1992, p. 103), os negros e pardos faleciam em proporções maiores (70,9\% e $61,6 \%$ respectivamente) que os internos brancos $(57,9 \%)$.

\section{V) CONSIDERAÇÕES FINAIS.}

A despeito das diferentes perspectivas teóricas pelas quais foi abordada a questão racial no discurso psiquiátrico brasileiro de fins do século XIX e início do XX, o negro - compreendido enquanto um 
grupo racial - apresentou-se, na maioria das vezes, como naturalmente e biologicamente inferior em relação a outros grupos.

Dessa forma, um dos resultados da introdução e recepção, no Brasil, de discursos e práticas produzidos nas sociedades disciplinares europeias (como o alienismo, o organicismo, a teoria da degenerescência, o hospício) teria sido, no contexto histórico-social específico de nossa sociedade, a reconfiguração do racismo étnico existente durante o período da escravidão (o africano de origem como o outro, o exterior) em nova forma de racismo.

A psiquiatria brasileira (em sua relação próxima com Estado), ao tematizar a questão racial (compreendendo a inferioridade do negro e a mestiçagem como ameaças internas ao desenvolvimento da nação), parece-nos ter configurado um episódio de racismo semelhante ao racismo interno e ao racismo de Estado, tais como descritos por Foucault $(1999,2010)$ em suas análises do contexto europeu ${ }^{17}$.

Se uma das características da biopolítica, ao tomar como objeto a população, seria “(...) o direito de fazer viver e deixar morrer" (Foucault, 1999, p. 287), a psiquiatria brasileira - ao defasar, no interior da sociedade, os negros em relação aos outros grupos - expôs a população negra à situações de morte, de “deixados para morrer”, no interior dos hospícios (como apontam os dados apresentados sobre o Hospital do Juquery, por exemplo).

Dessa forma, em conjunto com outras políticas como a concentração da população mais escura nas classes inferiores (com o consequente índice maior de mortalidades), a suposição da suposta incapacidade civilizatória do negro e a política de imigração europeia (Seyferth, p. 36), a psiquiatria, ao produzir a morte de indivíduos da população negra, teria também se apresentada como elemento integrante da proposta de "branqueamento" da nação, enquanto uma estratégia biopolítica de gestão da população brasileira ("Fazer viver a população branca, deixar morrer a população negra”).

Enfim, esse trabalho ao propor uma análise da questão racial a partir do quadro analítico desenvolvido por Foucault permitiu-

$17 \mathrm{O}$ que não significa que realizamos uma simples transposição dos esquemas analíticos de Foucault à realidade brasileira. Sobre o uso dos esquemas analíticos de Foucault para análise da sociedade brasileira, Cf. Alvarez, 2015, p. 28. 
nos desenvolver uma análise distinta daquelas realizadas nas obras que utilizamos como unidades de análise. Possibilitando-nos, assim, apontar certas resignificações e reposicionamentos da questão racial e do racismo na sociedade brasileira pós-abolição.

\section{REFERÊNCIAS}

ALVAREZ, M C. Michel Foucault e a Sociologia: aproximações e tensões. Estudos de Sociologia, Araraquara, Vol. 20, n³8, pp. 15-33, 2015.

AZEVEDO, C. M. M. de. Abolicionismo. Estados Unidos e Brasil, uma história comparada. São Paulo: AnnaBlume, 2003.

BARBOSA, R. M. Uma instituição modelar: o Hospício do Juquery. São Paulo em Perspectiva, São Paulo, Fundação Seade, Vol.6, no.4, pp.92-103, 1992.

BELUCHE, R. O corte da sexualidade: o ponto de viragem da psiquiatria brasileira no século XIX. São Paulo: Annablume, 2008.

CARNEIRO, M. L. T. Negros, Loucos Negros. Revista USP. Dossiê Brasil/ África, São Paulo, no. 18, pp. 144-151, 1993.

CUNHA, M. C. P. O espelho do mundo: Juquery, a história de um asilo. Rio de Janeiro: Paz e Terra, 1986.

. Cidadelas da ordem: a doença mental na República. São Paulo: Brasiliense, 1990.

DREYFUS, H.; RABINOW, P. Michel Foucault: uma trajetória filosófica - para além do estruturalismo e da hermenêutica. Rio de Janeiro: Forense Universitária, 1995.

ENGEL, M. G. As fronteiras da anormalidade: psiquiatria e controle social. História, Ciências, Saúde, Rio de Janeiro, Vol. 5, nº. 3, pp. 547-563, 1999.

Os delírios da razão: médicos, loucos e hospícios (Rio de Janeiro, 1830-1930). Rio de Janeiro: Editora FIOCRUZ, 2001.

FAUSTO, B. História do Brasil. São Paulo: Editora da USP. 1994.

FERNANDES, F. O negro no mundo dos brancos. São Paulo: Global, 2007.

FOUCAULT, M. História da Sexualidade: A Vontade de Saber (Vol. 1). Rio: Graal, 1985. 
. Vigiar e Punir: nascimento da prisão. Petrópolis: Vozes, 1987.

O sujeito e o poder. In: DREYFUS, H.; RABINOW, P. MICHEL FOUCAULT. Uma Trajetória Filosófica. Para além do estruturalismo e da hermenêutica. Rio de Janeiro: Forense Universitária, 1995, pp. 231-239.

. Em Defesa da Sociedade: curso no Collège de France (19751976). São Paulo: Martins Fontes, 1999.

. Foucault. In: Ditos \& Escritos V: Ética, Sexualidade, Política. Rio de Janeiro: Forense Universitária, 2003. pp. 234-239.

. Os anormais: curso no Collège de France (1974-1975). São Paulo: Martins Fontes, 2010.

Diálogo sobre o poder. In: Ditos e escritos IV - Estratégia Saber-Poder. São Paulo: Forense Universitária, 2012.

. Aulas sobre a vontade de saber: curso no Collège de France (1970-71). São Paulo: Martins Fontes, 2014.

O nascimento da medicina social. In: , Microfísica do poder. Organização e tradução de Roberto Machado. Rio de Janeiro: Edições Graal, 2016a, pp. 143170.

. Sobre a história da sexualidade. In: , Microfísica do poder. Organização e tradução de Roberto Machado. Rio de Janeiro: Edições Graal, 2016b, pp. 243-276.

FREDRICKSON, G. Racismo, uma breve história. Porto: Campo das Letras, 2004.

GUIMARÃES, A. S. Classes, raças e democracia. São Paulo: Editora 34, 2002.

HOFBAUER, A. O conceito de "raça" e o ideário do "branqueamento" no século XIX: bases ideológicas do racismo brasileiro. Teoria e Pesquisa, São Carlos (UFSCar), Vol. 42 e 43, pp. 63-110, 2003.

Ações afirmativas e o debate sobre racismo no Brasil. Lua Nova, São Paulo, nº. 68, pp. 9-56, 2006.

HUND, W. Inclusion and exclusion: dimensions of racism. Wiener Zeitschrift zur Geschichte der Neuzeit, Vol. 1, pp. 6-19, 2003. 
LIMA BARRETO, A. H. de. Diário do hospício e O cemitério dos vivos. São Paulo: Cosac Naify, 2010.

LOBO, L. F. Os infames da história: pobres, escravos e deficientes no Brasil. Rio de Janeiro: Lamparina, 2008.

MACHADO, R. Introdução: Por uma genealogia do poder. In: FOUCAULT, M. Microfísica do poder. Organização e tradução de Roberto Machado. Rio de Janeiro: Edições Graal, 2016. pp. 7-34.

MUNANGA, K. Uma abordagem conceitual das noções de raça, racismo, identidade e etnia. In: SEMINÁRIO NACIONAL RELAÇOES RACIAIS E EDUCAÇÃO-PENESB. Rio de Janeiro, 2003. Anais... Rio de Janeiro, 2003. Disponível em: <http://www. acaoeducativa.org.br/downloads/09abordagem.pdf $>$. Acesso em: 26 de agosto de 2017.

ODA, A. M. G. R. A teoria da degenerescência na fundação da psiquiatria brasileira: contraposição entre Raimundo Nina Rodrigues e Juliano Moreira. Psychiatry Online Brazil - part of The International Journal of Psychiatry, Vol. 6, nº. 12, 2001. Disponível em: <www. polbr.med.br/arquivo/wal1201.htm>. Acesso em: 30 de agosto de 2017.

PATTO, M. H. S. Estado, ciência e política na Primeira República: a desqualificação dos pobres. Estudos Avançados. São Paulo, Vol. 13, no. 35, pp. 167-198, 1999.

PENA, S. D. J. Razões para banir o conceito de raça da medicina brasileira. História, Ciências, Saúde, Rio de Janeiro, Vol. 12, no. 2, pp. 321346, 2005.

POL-DROIT, R. Michel Foucault: entrevistas. São Paulo: Graal, 2006.

PORTOCARRERO, V. Arquivos da loucura: Juliano Moreira e a descontinuidade histórica da psiquiatria. Rio de Janeiro: Editora FIOCRUZ, 2002.

RIBEIRO, P. S. Prescrições médicas contra os males da nação: diálogos de Franco da Rocha na construção das Ciências Sociais no Brasil. 2010. Dissertação (Mestrado) - Universidade Estadual Paulista, Faculdade de Ciências e Letras de Araraquara, 156 f. Disponível em: <http://hdl.handle.net/11449/98980>. Acesso em: 30 de agosto de 2017.

SCHWARCZ, L. M. O espetáculo das raças: cientistas, instituições e 
questão racial no Brasil - 1870-1930. São Paulo: Companhia das Letras, 1993.

Nem preto nem branco, muito pelo contrário: cor e raça na intimidade. In: NOVAIS, F. A. e SCHWARCZ, L. M. História da vida privada (Vol.IV). São Paulo: Companhia das Letras, 1998, pp. 173-243.

SEVCENKO, N. Introdução. O prelúdio republicano, astúcias da ordem e ilusões do progresso. In: História da vida privada no Brasil República: da Belle Époque à Era do Rádio. São Paulo: Companhia das Letras, 1998, v.3.

. A Revolta da Vacina: mentes insanas em corpos rebeldes. São Paulo: Cosac Naify. 2010.

SEYFERTH, G. O beneplácito da desigualdade: breve digressão sobre racismo. In: SEYFERTH, G. et al. Racismo no Brasil. São Paulo: Editora Fundação Peirópolis, 2002. pp. 17-43.

VIVEIROS DE CASTRO, E. Os pronomes cosmológicos e o perspectivismo ameríndio. Mana, Rio de Janeiro, Vol. 2, nº 2, pp. 115-144, 1996.

, Eduardo. Perspectivismo e multinaturalismo na América indígena. O que nos faz pensar, Rio de Janeiro, Vol. 14, nº 18, pp. 225-254, 2004.

WADE, P. Race, nature and culture. Mana, nº. 28, pp. 17-34, 1993.

WEYLER, A. R. A loucura e a república no Brasil: a influência das teorias raciais. Psicologia USP, São Paulo, Vol. 17, nº. 1, pp. 17-34, 2006.

Recebido em: 11/10/2017. Aprovação final em: 22/12/2017. 
